\title{
CAPÍTULO 39: ESTUDOS PRÉVIOS PARA O ENCAPSULAMENTO DE COMPOSTOS USANDO AÇAÍ, WHEY PROTEIN E CARRAGENA
}

\section{CHAPTER 39: PREVIOUS STUDIES FOR THE ENCAPSULATION OF COMPOUNDS USING AÇAÍ, WHEY PROTEIN AND CARRAGENA}

\author{
Jaqueline de Jesus Silva ${ }^{1}$; Tailane Vieira $\operatorname{Costa}^{2}$; Mirela Luz Santos ${ }^{3}$ Laís Teles da Silva e Silva ${ }^{4}$; \\ Modesto Antônio Chaves ${ }^{5}$
}

\begin{abstract}
Resumo
Diversos materiais podem ser usados como encapsulantes ou coadjuvantes do encapsulamento como é o caso da carragena, cujo objetivo desse trabalho está em verificar o efeito da carragena sobre as propriedades da solução encapsulante. Dessa forma o efeito foi testado quanto a variação do teor de sólidos solúveis, $\mathrm{pH}$ e cor dos tratamentos com 0 h e 24 h em proporções de $0 \%$ a 5\% de carragena na mistura de açaí e whey protein. Também se avaliou a estabilidade da solução utilizando microscópio óptico com uma câmera digital acoplada em uma das lentes. Dimensionou-se o diâmetro médio das bolhas e sua variação com o tempo em função do teor de carragena. O efeito sobre os sólidos solúveis (SS) e o pH do meio, observou-se pequenas alterações que podem ter contribuído ao acaso para aumentar SS e elevar o pH da solução. As coordenadas de cor sofreram efeito do tempo em todas as concentrações de carragena e do teor de carragena apenas com o tempo da análise de $0 \mathrm{~h}$ para luminosidade, em $24 \mathrm{~h}$ para o h ${ }^{\circ}$ e em 0 e 24 $\mathrm{h}$ para cromaticidade. A adição de carragena não apresentou contribuição significativa para manter a estabilidade das partículas.
\end{abstract}

Palavras-Chaves: coadjuvantes, carragena, encapsulamento, material de parede, proteína.

\begin{abstract}
Several materials can be used as encapsulants or adjuvants in the encapsulation, as is the case of carrageenan, whose objective of this work is to verify the effect of carrageenan on the properties of the encapsulating solution. Thus, the effect was tested for variation in the content of soluble solids, $\mathrm{pH}$, and color of the treatments with $0 \mathrm{~h}$ and $24 \mathrm{~h}$ in proportions of $0 \%$ to $5 \%$ of carrageenan in the mixture of açaí and whey protein. The stability of the solution was also evaluated using an optical microscope with a digital camera attached to one of the lenses. The average diameter of the bubbles and their variation with time were dimensioned according to the content of carrageenan. In the effect on soluble solids (SS) and $\mathrm{pH}$ of the medium, small changes were observed that may have contributed at random to increase SS and increase the $\mathrm{pH}$ of the solution. The color coordinates were measured in all carrageenan concentrations and carrageenan content only with the time of analysis of $0 \mathrm{~h}$ for luminosity, in $24 \mathrm{~h}$ for $\mathrm{h}^{\circ}$ and in 0 and 24 $\mathrm{h}$ for chromaticity. The addition of carrageenan did not make a significant contribution to maintaining the stability of the particles.
\end{abstract}

Keywords: adjuvants, carrageenan, encapsulation, wall material, protein.

\section{Introdução}

O processo de encapsulação consiste em transformar uma solução ou emulsão, do estado líquido para o sólido na forma de pó de modo a criar uma capsula, que com um

\footnotetext{
${ }^{1}$ Mestrado em engenharia e ciência de alimentos, UESB, jaqsali@live.com

2 Engenharia de alimentos, UESB, tai_vieira2011@hotmail.com

${ }^{3}$ Engenharia de alimentos, UESB, mirela_luz@ hotmail.com

${ }^{4}$ Mestrado em engenharia e ciência de alimentos, UESB, laiseteles.silva@gmail.com

${ }^{5}$ Doutor, UESB, modestochaves@ hotmail.com
} 
agente encapsulante forma uma capa protetora envolvendo o material de interesse em um núcleo, vários núcleos ou núcleos dispersos como microesferas (JAFARI et al., 2008). Dessa forma esse sistema de cápsula, tem a função de proteger, manter a estabilidade, evitar perdas, oxidação, controlar a liberação do material de interesse e obter produtos com maior solubilidade e melhores características sensoriais e nutricionais, podendo assim ser disponibilizados como ingredientes em outras preparações alimentícias, formando uma barreira física entre o composto encapsulado e o material de parede, que também é alimentício (FAVARO-TRINDADE e PINHO, 2008).

O composto de interesse neste caso está contido no açaí e faz referência a grande quantidade de antocianina e outros flavonoides com propriedades antioxidantes, antiinflamatórias e anticancerígenas e apresenta também elevado valor energético e proteico e como consequência, tem sido considerado um alimento funcional por gerar inúmeros benefícios à saúde (KANG et al., 2012; PORTINHO; ZIMMERMANN; BRUCK, 2012). Esses elementos podem ser degradados ao longo do processo de encapsulação, por isso, se faz necessário um estudo prévio de variáveis que possam indicar se haverá eficiência na encapsulação após a secagem da solução em estudo.

Para garantir a proteção desses elementos, a capa protetora que se forma em seu entorno pode ser constituída de diversos materiais, e os componentes protéicos tem sido amplamente utilizada como encapsulante (SANTANA et al.,2016; KYRIAKOUDI e TSIMIDOU, 2018; CHUYEN et al., 2019). A eficiência das proteínas do soro de leite como agente encapsulante se dá por sua habilidade de interagir com água, pequenos íons e outros polímeros presentes na grande área interfacial, que em geral é termodinamicamente desfavorável, essas proteínas estabilizam as gotas formadas na homogeneização e reduzem suas taxas de coalescência (WALSTRA, 2007; YANG, et al., 2020), diminuindo a tensão superficial tanto quanto os surfactantes, fazendo com que a saturação efetiva da superfície seja atingida em concentrações molares 100 vezes menores do que os surfactantes de baixo peso molecular (JAYASUNDERA et al., 2009; YANG, et. al., 2020). Logo, é possível preservar a estabilidade da emulsão e retardar a coalescência com os peptídeos contidos nas proteínas do soro de leite cujos pesos moleculares são maiores que $2 \mathrm{kDa}$ (SCHRODER et al. 2017).

Outros componentes usados no processo de encapsulação são os coadjuvantes, entre eles estão as carragenas que são grupos de galactanas sulfatadas extraídas de algas vermelhas, muito utilizadas em industrias pela capacidade que elas têm de aumentar a viscosidade de soluções e formar géis firmes (FENNEMA, DAMODARAN e PARK, 2010; BARRETT, 2018). Estudos relatam que a combinações entre carragenas e proteínas 
de várias fontes concomitantemente podem melhorar a retenção e proteção de substâncias voláteis e características das superfícies esféricas das microcápsulas (LAURENTI e GARCIA, 2013).

Presume-se que a encapsulação pode ser melhorada quando se conhece a natureza da dispersão formada antes da secagem, ao se mensurar parâmetros como distribuição e tamanho das partículas (CARMONA, 2011). As gotículas mantêm-se em movimento desordenado graças à repulsão entre suas cargas elétricas, então se recomenda a diminuição máxima do tamanho das gotículas e uniformidade entre elas para manter sua estabilidade até o momento da secagem (FRANZOL, REZENDE, 2015; Yang et. al., 2020).

É de suma importância que se estude previamente o tamanho da cápsula, pois há uma influência diretamente na liberação controlada do material do núcleo, podendo apresentar liberação em velocidade constante quando as partículas são menores, ou rápida liberação quando as partículas são maiores (SANTOS, 2014). Um dos fatores que também podem ser estudados previamente é o tipo e a composição do material de parede pois este interfere no tamanho e distribuição das partículas e em propriedades importantes de produtos encapsulados, como teor de água, solubilidade, higroscopicidade, entre outras (TONON, GROSSO e HUBINGER, 2011).

Pelos motivos supracitados, a seleção do material de parede é uma etapa crítica dos estudos prévios, pois ela tem influência direta nas propriedades da solução antes da secagem, na retenção dos voláteis durante o processo e na vida de prateleira do pó encapsulado depois da secagem (JAFARI et al., 2008). Os critérios para a seleção do material de parede estão principalmente baseados em suas propriedades físico-químicas e devem ser de baixa viscosidade, higroscopicidade, insolúveis e não reativos com o núcleo, de baixo custo e fácil acesso (TONON, GROSSO e HUBINGER, 2011; CHUYEN et al., 2019).

Vê-se que é grande a demanda de característica em um material ideal, por isso, desde muito tempo já se relatava que combinações de diferentes matérias podem resultar em um produto final de melhor qualidade e cada combinação precisa ser estudada caso a caso (FAVARO-TRINDADE e PINHO, 2008). Diante disso, o objetivo desse trabalho foi fazer um estudo prévio de possíveis interferentes do processo de encapsulamento, levando em conta o uma combinação de diferentes materiais de parede e o tempo entre o preparo da solução até um limite máximo de repouso até a hora da secagem. Avaliando para isso, as variações de sólidos solúveis (SS), pH, cor, e tamanho das partículas formadas. 


\section{Material e Métodos}

\section{Local do experimento}

O experimento foi realizado no Centro de Desenvolvimento e Difusão de Tecnologias (CEDETEC) da Universidade Estadual do Sudoeste da Bahia - Campus Itapetinga.

\section{Matéria prima}

A polpa de açaí congelada foi obtida no município de Itororó-BA, numa unidade onde se cultiva e manipula açaí orgânico, ao chegar no local do experimento foi mantida em freezer horizontal à $-18^{\circ} \mathrm{C} \pm 2^{\circ} \mathrm{C}$, por cerca de 30 dias. Antes do uso a polpa foi descongelada e filtrada por pressão positiva em filtro de tecido voil, com a finalidade de separar partículas em suspensão.

\section{Avaliação do uso da carragena}

Foi preparado uma mistura de açaí, proteína e diferentes proporções de carragena para verificar a contribuição da carragena na melhoria das propriedades da solução. As proporções estudas foram 2\%; 3\%; 4\%; 5\% obtendo-se cinco tratamentos T1, T2, T3, T4 e T5, sendo T1 a testemunha, ou seja, tratamento sem adição de carragena. Em todos os tratamentos foram mantidos o percentual fixo de material de parede de $25 \%$.

\section{Formação da solução}

A formação da solução foi realizada por meio da homogeneização de cada tratamento em um dispersor, do tipo rotor-estator de alto desempenho (modelo T18 digital ULTRA-TURRAX) na velocidade de $14000 \mathrm{rpm}$ por 10 minutos.

Os tratamentos foram submetidos a análise de sólidos solúveis, $\mathrm{pH}$, cor e tamanho e distribuição de partículas, conforme metodologias descritas nos itens seguintes.

\section{Sólidos Solúveis (SS), pH e cor da emulsão}

As medições de SS, pH e cor foram realizadas no tempo de 0 horas (h), que corresponde a análise feita logo após o término da homogeneização e após $24 \mathrm{~h}$.

A determinação do teor de SS totais dos tratamentos foi realizada por meio da refratometria em Refratômetro de bancada (DSA E-Scan), com escala graduada em ${ }^{\circ}$ Brix a $20^{\circ} \mathrm{C}$.

A medida do $\mathrm{pH}$ foi realizada em $\mathrm{pH}$-metro digital (modelo Akso) por leitura direta imergindo um eletrodo nas amostras (AOAC, 2016). 


\section{Determinação instrumental dos parâmetros de cor}

A cor foi determinada pelo sistema Hunter Lab em colorímetro Colorquest XE (HunterLab, Sunset Hills Reston, VA, EUA), iluminante D65 e observador $10^{\circ}$, com reflexão inclusa calibrado a cada batelada de medições, conforme solicitado pelo software do próprio instrumento. Foram obtidos os parâmetros de cor Lab, referentes a luminosidade, cromaticidade e o ângulo do tom a partir dos parâmetros a e b, em que foram calculadas as coordenadas cilíndricas $\mathrm{C}^{*} \mathrm{e} \mathrm{h}^{\circ}$ de acordo com as equações 1 e 2 . $C^{*}=\left(a^{2}+b^{2}\right)^{1 / 2}$

$$
h^{\circ}=\arctan \left(\frac{b}{a}\right)
$$

Onde $\mathrm{C}^{*}$ define o croma ou a cromaticidade $\mathrm{h}^{\circ}$ representa o ângulo de tom.

\section{Tamanho e distribuição das partículas}

O tamanho e a distribuição das partículas dos tratamentos foram observados em microscópio óptico, tomando-se uma alíquota em lâmina coberta por uma lamínula e medido, tomando como referência uma lâmina graduada em milímetros (mm).

Com o auxílio de uma câmera digital (MEKEY SCMOS mini USB2.0 SCMOS00350KPA) acoplada ao microscópio óptico binocular foram obtidas as imagens em 5 tempos, imediatamente após a homogeneização (0h) e após 1, 2, 3 e 24 horas, de forma a verificar a estabilidade das partículas a partir da variação dos diâmetros e sua distribuição. Com auxílio do software ImageView versão x64,3.7.10121.20171030 os dados foram coletados numa ampliação microscópica de 40X, calibrados e convertidos de pixels para $\mu \mathrm{m}$ com uma lâmina de calibração de 2,0 $\mathrm{mm}$ gerando imagens de $914,28 \mu \mathrm{m}$ por $685,71 \mu \mathrm{m}$.

\section{Análises estatísticas}

Foi realizado um delineamento inteiramente casualizado em um esquema fatorial $2 \times 5$ com 3 repetições em que testou-se a significância da interação entre o teor de carragena em 5 níveis $(0 \%, 2 \%, 3 \%, 4 \%$ e 5\%) e tempo em dois níveis (0h e 24h) por meio de análise de variância (ANOVA) e obteve-se os modelos de regressão utilizando o programa estatístico Statystical Analysis System (SAS)® Studenty.

Os diâmetros médios das bolhas foram coletados e avaliados segundo várias equações de regressão envolvendo curvas com pico sendo que a equação de Hubbert foi a que apresentou o melhor resultado. Uso-se para isso o software OriginLab $2017 \mathrm{com}$ o qual também se obtiveram gráficos de dispersões. 


\section{Resultados e Discussão}

\section{Efeito da adição de carragena}

\section{Determinação de SS}

A interação entre o teor de carragena e o tempo da análise foi não significativo $(\mathrm{P}>0,05)$ para descrever a variação no teor de SS. Em vista disso, se fez necessário avaliar a ação dos dois fatores sob SS separadamente. Para o parâmetro teor de carragena o ajuste foi muito baixo $\left(\mathrm{R}^{2}\right.$ de 0,46$)$ e o tempo da análise foi não significativo $(\mathrm{P}>0,05)$ para indicar alterações no teor de SS. Portanto, não foi possível ajustar o modelo polinomial que explicasse as possíveis variações apresentadas, podendo ser uma variação devida ao acaso.

O teor de SS variou numericamente entre 28 e $30^{\circ}$ Brix, o qual está de acordo com o valor apresentado no trabalho de encapsulamento de alimentos realizado por Jafari, Ghalenoei, e Dehnad (2017) relatando que índice semelhante a este pode gerar um material em pó com rendimento em torno de $25 \%$, densidade mínima de $0,747 \mathrm{~g} / \mathrm{mL}$, alta solubilidade e aponta que o aumento da concentração de sólidos pode ser prejudicial ao aprisionamento de compostos. Muzaffar, et al., (2016) encontraram melhores resultados de rendimento do pó com o teor do material encapsulante acima de $20 \%$. Sabe-se que as carragenas são espessantes de alto pesso molecular que aumentam o a viscosidade da solução sem alterar o seu teor de sólidos (KULKARNI e SHAW, 2016). Ou seja, neste intervalo de concentração de sólidos solúveis na mistura é possível melhorar o rendimento, a solubilidade em água e densidade, mas é possível que a alta viscosidade dificulte a fluidez na solução de alimentação e os trabalhos da área buscam sempre por materiais de parede de baixa viscosidade (KYRIAKOUDI e TSIMIDOU, 2018; CHUYEN et. al., 2019).

\section{Determinação do pH}

A interação entre o teor de carragena com o tempo da análise mostrou-se não significativa $(\mathrm{P}>0,05)$ para verificar a variação de $\mathrm{pH}$.

Ambos os fatores separadamente mostraram-se significativos $(\mathrm{P}<0,05)$ para alterar $\mathrm{pH}$ porém teor de carragena apresentou $\mathrm{R}^{2}$ de 0,22 e tempo para análise apresentou $\mathrm{R}^{2}$ de 0,25 , ou seja, não foi possível ajustar uma equação para descrever a variação de $\mathrm{pH}$ em função do teor de carragena e do tempo.

A faixa de $\mathrm{pH}$ encontrada de 5,55 a 5,80 é um valor distante do ponto isoelétrico (PI) das proteínas do soro e pode dificultar os desdobramentos. As proteínas do soro de leite, quando estão afastadas do seu ponto isoelétrico $(\mathrm{PI}=\mathrm{pH} 4,6)$ apresentam uma 
estrutura tetramerizada, (FENNEMA, DAMODARAN, e PARK, 2010), já as carragenas se estabilizam em pH 6 e são pouco afetadas pelas alterações de pH (KULKARNI e SHAW, 2016). Porém de acordo com Stone e Nickerson, (2012) a interação carragenaproteína forma um complexo estabilizado por forças eletrostáticas, de Van der Waals, interações hidrofóbicas, ligações de hidrogênio e de dissulfeto com dissacarídeos, consequentemente se torna menos disponível ao desdobramento e aprisionamento de compostos durante a encapsulação. Ou seja, não as condições de $\mathrm{pH}$ presente, não foi afetada por meio da presença ou concentração de carragena, também não puderam tornar as proteínas do soro de leite mais disponíveis ao encapsulamento de compostos.

\section{Determinação instrumental da cor}

Os dados obtidos de luminosidade estão apresentados na Tabela 1.

Tabela 1 - Luminosidade em função do teor de carragena na solução encapsulante com o tempo da análise.

\begin{tabular}{ccc}
\hline & \multicolumn{2}{c}{ Luminosidade } \\
\cline { 2 - 3 } Teor de carragena (\%) & $0 \mathrm{~h}$ & $24 \mathrm{~h}$ \\
\cline { 2 - 3 } 0 & 40,62 & 26,61 \\
2 & 76,81 & 35,73 \\
3 & 58,65 & 26,00 \\
4 & 40,97 & 27,01 \\
5 & 39,93 & 27,01 \\
\hline
\end{tabular}

Fonte: própria

De acordo com o teste $\mathrm{F}$ da análise de variância com $\mathrm{P}<0,05$ o fator tempo da análise e teor de carragena e sua interação foi significativa. A luminosidade poderia ter sido alterada simultaneamente pelo tempo da análise nas concentrações de carragena e pelo teor de carragena apenas com o tempo da análise de $0 \mathrm{~h}$, porém o fator de ajuste da equação foi de 0,15 mostrando que as alterações observadas podem ter sido devido ao acaso.

No sistema CIE L*a*b* a luminosidade representa o quanto da cor branca ou claridade e preta ou escuridão está presente na amostra, e é representada por valores que variam de 100 a 0 respectivamente (MCKEEN, 2014; BERTALMÍO, 2020). Dessa forma, os dados obtidos indicam que a luminosidade apresenta um ponto de máximo indicando claridade e depois diminui indicando escurecimento com o tempo da análise e com o teor de carragena, o que pode ser explicado pela oxidação de espécies reativas contidas nas amostras (ARAÚJO, 2006), nesse caso, é possível que seja pela oxidação das antocianinas presentes no açaí que também são responsáveis pela sua coloração original. 
A avaliação do tempo da análise de $24 \mathrm{~h}$ em função do teor de carragena mostrou que não houve alterações na luminosidade, mas no tempo de $0 \mathrm{~h}$ a luminosidade variou em função do teor de carragena. Essa variação foi representada por um modelo quadrático cujo $\mathrm{R}^{2}$ foi de 0,96 (Eq. 3) e pela Figura 1 onde mostra o efeito da concentração de carragena no tempo $0 \mathrm{~h}$ sobre a luminosidade

$L=40,041+2,580$ Car $-0,772 \operatorname{Car}^{2}$

Sendo $L$ o luminosidade da cor e Car o teor de carragena em percentual.

Figura 1 - Efeito do teor de carragena no tempo 0h sobre a luminosidade na solução encapsulante.



Fonte: própria.

De acordo com a imagem acima, vê-se que a luminosidade apresenta um ponto máximo e diminui com a sucessiva adição de carragena na solução. Ou seja, assim, como mostram os coeficientes da equação gerada, o aumento gradativo no teor de carragena escurece as amostras. É necessário salientar que quando há mudanças na luminosidade haverá também mudança na saturação da cor, pois no sistema CIE L*a*b*a cor é um conjunto de coordenadas que se posiciona em um espaço tridimensional, cujo eixo da luminosidade é vertical e quando houver mudança em uma das coordenadas forçará a movimentação das demais (BERTALMÍO, 2020). Como pode ser observado na avaliação da cromaticidade e ângulo $\mathrm{h}^{\circ}$.

A cromaticidade indica o quão intensa é a cor presente na amostra e é uma composição das coordenadas a* e b*, as quais ocupam os eixos horizontais no espaço e não apresentam limites numéricos específicos, mas suas posições indicam a cor da amostra, quando o valor de $\mathrm{a}^{*}$ for positivo é vermelho, se for negativo é verde, e o valor 
de b* positivo é amarelo e negativo é azul (McKeen, 2014). Desse modo, os dados obtidos da cromaticidade estão apresentados na Tabela 2.

Tabela 2 - Cromaticidade em função do teor de carragena na solução encapsulante em diferentes tempos da análise.

\begin{tabular}{ccc}
\hline & \multicolumn{2}{c}{ Cromaticidade } \\
\cline { 2 - 3 } Teor de carragena (\%) & $0 \mathrm{~h}$ & $24 \mathrm{~h}$ \\
\cline { 2 - 3 } 0 & 09,94 & 07,62 \\
2 & 09,82 & 07,82 \\
3 & 08,98 & 06,52 \\
4 & 09,33 & 07,50 \\
5 & 06,78 & 08,27 \\
\hline
\end{tabular}

Fonte: própria

$\mathrm{O}$ teste $\mathrm{F}$ da análise de variância foi significativo com $\mathrm{P}<0,05$ para o fator tempo da análise e teor de carragena e a interação entre eles. A cromaticidade foi alterada simultaneamente pelo tempo da análise com as concentrações de carragena e pelo teor de carragena com o tempo da análise.

Com os dados da tabela acima, vê-se que os dados obtidos indicam que a cromaticidade diminui com o tempo da análise com as concentrações de carragena e tanto o tempo de $0 \mathrm{~h}$ quanto de $24 \mathrm{~h}$ houveram diferenças significativas com $\mathrm{P}<0,05$ em relação as concentrações de carragena, ou seja, a presença da carragena acarreta mudança na intensidade da cor da amostra com o tempo. Tal fato foi representado por duas equações de grau 3 com respectivos $\mathrm{R}^{2}$ de 0,90 e $\mathrm{R}^{2}$ de 0,87 (Eq. 4 e 5) e os gráficos da Figura 2 que mostram o efeito da concentração de carragena no tempo da análise de 0 h e $24 \mathrm{~h}$ sobre a cromaticidade.

$C_{0 h}=9,967-1,0229 \operatorname{Car}+0,6166 \operatorname{Car}^{2}-0,1069 \operatorname{Car}^{3}$

$C_{24 h}=7,6797+0,9856 \mathrm{Car}-0,7055 \mathrm{Car}^{2}+0,1071 \mathrm{Car}^{3}$

Sendo $C_{0 h}$ a cromaticidade da cor no tempo da análise de $0 \mathrm{~h}, C_{24 h}$ a cromaticidade no tempo de $24 \mathrm{~h}$ e Car o teor de carragena em percentual. 
Figura 2 - Efeito do teor de carragena com o tempo da análise sobre a cromaticidade na solução encapsulante.

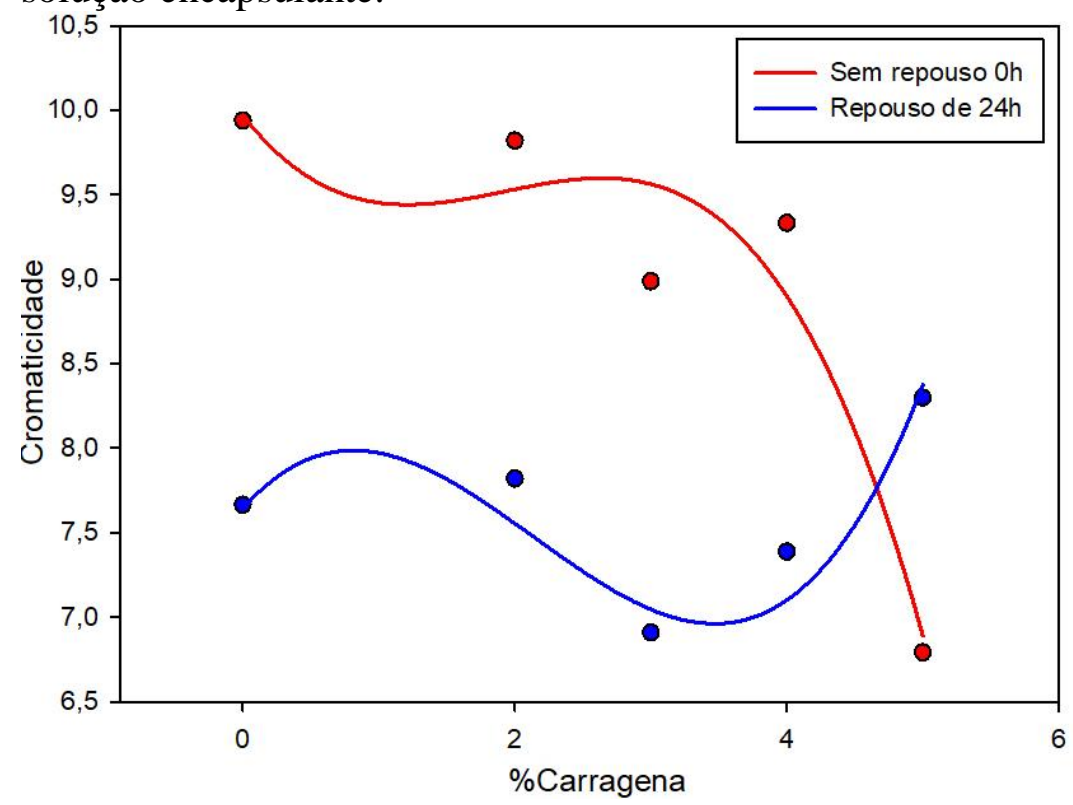

Fonte: própria

De acordo com a figura acima, a cromaticidade inicial é menor no tempo da análise de 24 h e que na concentração máxima de carragena a cromaticidade é menor no tempo $0 \mathrm{~h}$ e maior em $24 \mathrm{~h}$. Ou seja, aumento gradativo no teor de carragena reduz a cromaticidade imediatamente após a homogeneização tempo da análise de $0 \mathrm{~h}$.

Em relação ao ângulo $h^{\circ}$ tem-se que sua definição faz referência tonalidade ou a cor propriamente dita e também é obtida de uma composição das coordenadas a* e b* (BERTALMÍO, 2020). Os dados obtidos do h $^{\circ}$ estão apresentados na Tabela 3.

Tabela $3-\mathrm{h}^{\circ}$ da cor em função do teor de carragena na solução encapsulante com o tempo da análise.

Teor de carragena $(\%)$

0

2

3

4

5

\begin{tabular}{cc}
\multicolumn{3}{c}{$\mathrm{h}^{\circ}$} \\
\hline $0 \mathrm{~h}$ & $24 \mathrm{~h}$ \\
\hline 0,61 & 0,58 \\
0,62 & 0,55 \\
0,68 & 0,59 \\
0,76 & 0,58 \\
0,65 & 0,73
\end{tabular}

Fonte: própria

De acordo com o teste $\mathrm{F}$ da análise de variância com $\mathrm{P}<0,05$ os dois fatores em estudo tempo da análise e teor de carragena e a interação entre eles foram significativos, ou seja, os tratamentos foram alterados simultaneamente pelo tempo da análise nas concentrações de carragena e pelo teor de carragena com o tempo da análise de $24 \mathrm{~h}$. Nesse tempo o $\mathrm{h}^{\circ}$ diferiu significativamente pelo teste $\mathrm{F}$ da anova com $\mathrm{P}<0,05$ em relação ao tempo da análise em cada uma das concentrações de carragena e que tanto no tempo da 
análise de $0 \mathrm{~h}$ quanto em $24 \mathrm{~h}$ houveram diferenças significativas em relação as concentrações de carragena.

Tais diferenças foram representadas por equação de grau 3 com $R^{2}$ de 0,93 e $R^{2}$ de 0,81 (Eq. 6 e 7) e em gráficos na Figura 3 que mostram o efeito da concentração de carragena no tempo da análise de $0 \mathrm{~h}$ e $24 \mathrm{~h}$ sobre o $\mathrm{h}^{\circ}$.

$H_{0 h}=0,6124-0,1585 \operatorname{Car}+0,107 \operatorname{Car}^{2}-0,0148 \operatorname{Car}^{3}$

$H_{24 h}=0,5765+0,0271 \mathrm{Car}-0,0286 \mathrm{Car}^{2}+0,0058 \mathrm{Car}^{3}$

Sendo $H_{0 h} \mathrm{O} \mathrm{h}^{\circ}$ no tempo da análise de $0 \mathrm{~h}, H_{24 h} \mathrm{o} \mathrm{h}^{\circ}$ tempo da análise de $24 \mathrm{~h}$ e Car o teor de carragena em percentual.

Figura 3 - Efeito do teor de carragena tempo da análise sobre $o h^{\circ}$ na solução encapsulante.

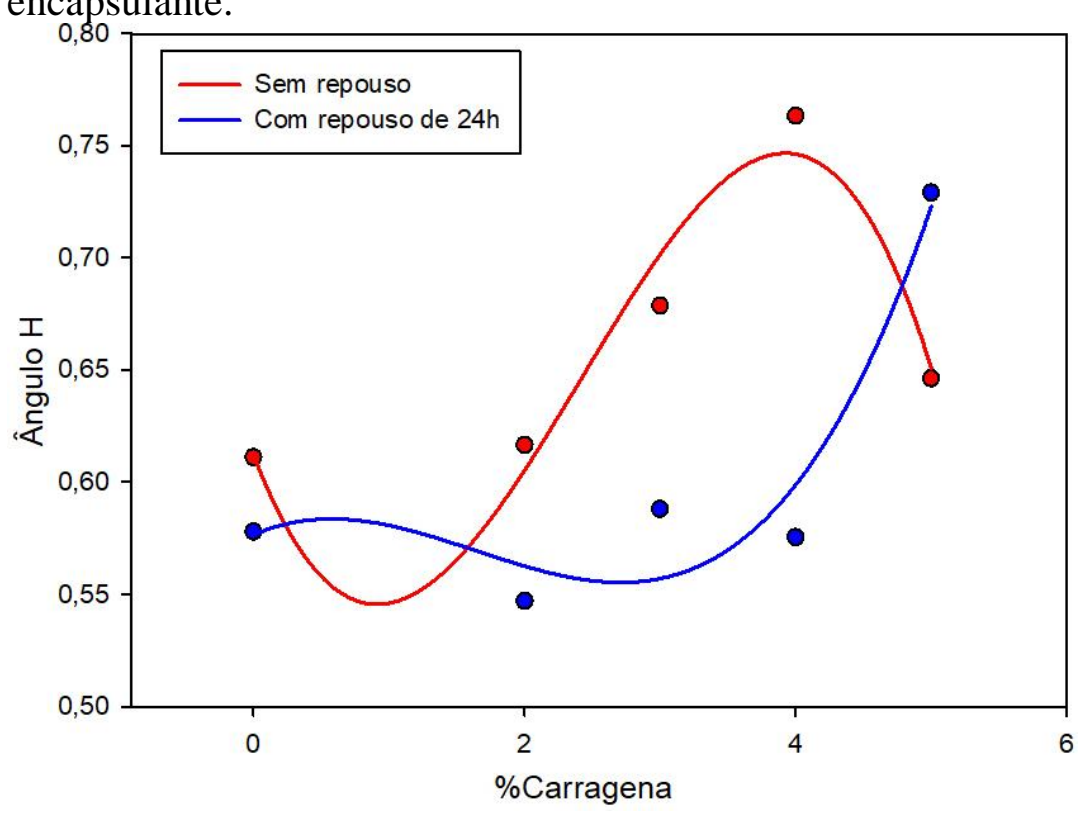

Fonte: própria.

Vê-se que $\mathrm{o} \mathrm{h}^{\circ}$ no tempo da análise de $0 \mathrm{~h}$ apresenta tendência ao aumento com aumento da concentração de carragena. Após 24 h o aumento da concentração leva ao aumento no valor do ângulo $\mathrm{H}$.

Obteve-se valores de luminosidade mínimos que variaram em torno de 40 e 26 no tempo da análise $0 \mathrm{~h}$ e $24 \mathrm{~h}$ respectivamente, a cromaticidade mínima e máxima variou entre 6,5 e 9,9 e os valores do ângulo ${ }^{\circ}$ variaram entre 0,61 a 0,76 demarcando a cor dos tratamentos em 0 h e 24 h na região avermelhada com luminosidade e saturação baixas (BERTALMÍO, 2020). É possível que essa coloração muito clara tenha forte influência dos materiais encapsulantes, que costumam ser brancos (TONON, BRABET e HUBINGER, 2009) e da incorporação de ar, que facilita o espalhamento da luz e pode ter alterado os dados de cor obtidos (ZÍLIO, 2009; CARNEIRO, 2011). 


\section{Tamanho e distribuição das partículas}

Observou-se, após a homogeneização da emulsão, a presença de bolhas em todos os tratamentos que podem ser observados nas imagens da Figura 4.

Figura 4 - Bolhas presentes após a homogeneização nos tratamentos com e sem adição de carragena em diferentes tempos de captura das imagens com ampliação de 40X.

$\mathrm{Oh}$



$1 \mathrm{~h}$
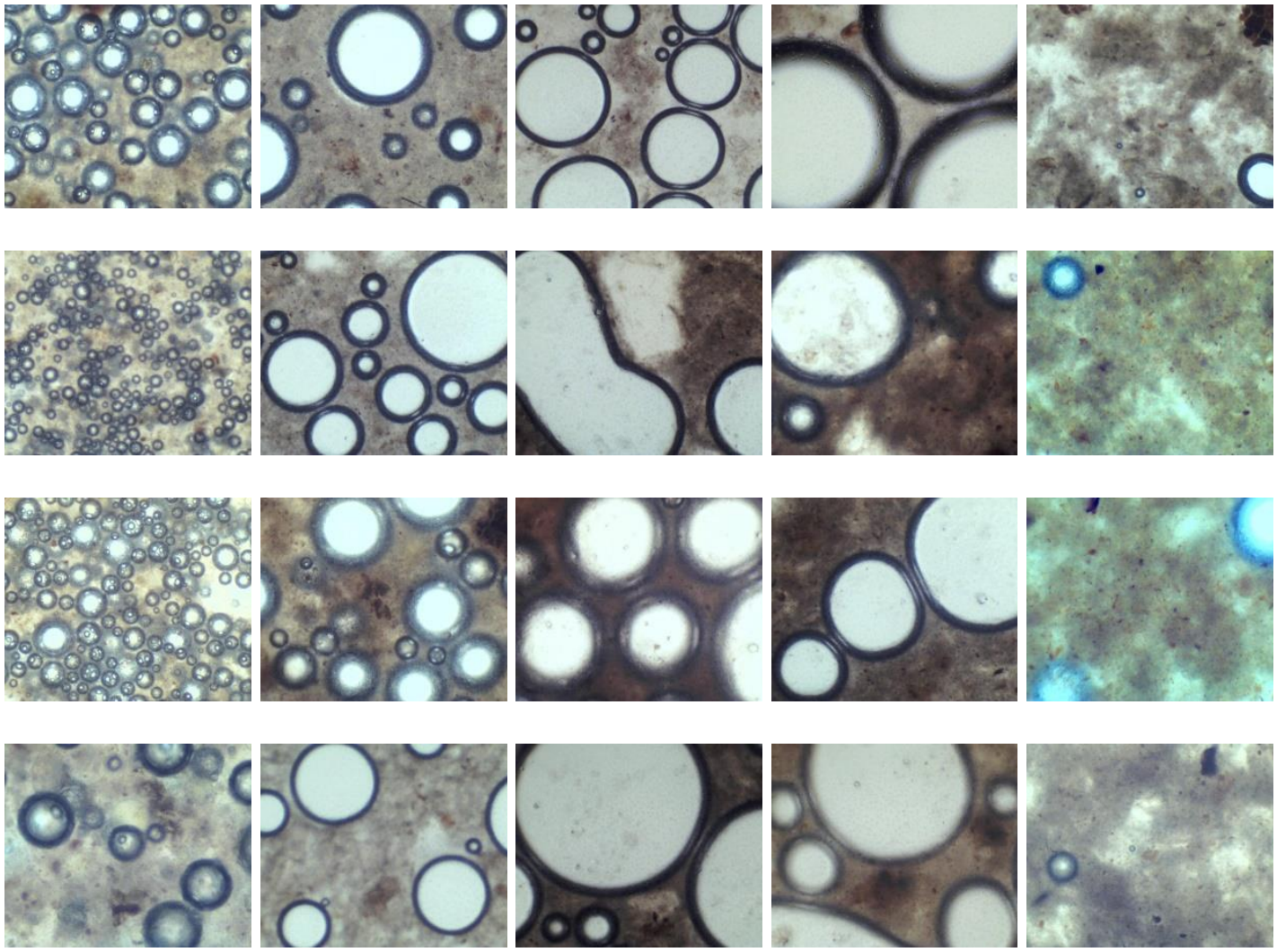

T5
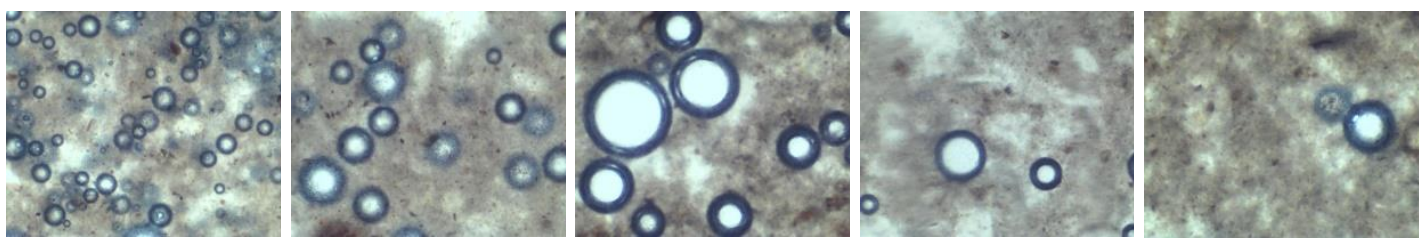

Legenda: $\mathrm{T} 1=0 \%$ carragena, $\mathrm{T} 2=1 \%$ de carragena, $\mathrm{T} 3=3 \%$ de carragena, $\mathrm{T} 4=4 \%$ de carragena e $\mathrm{T} 5=5 \%$ de carragena.

Fonte: própria.

Observou-se em todos os tratamentos que imediatamente após a homogeneização houveram inúmeras bolhas e, à medida que o tempo passou elas cresceram e movimentaram-se. Dessa maneira com 1 h, o número de bolhas menores diminui e começou a surgir gotas maiores, e em menor quantidade.

Esse comportamento continuou até $3 \mathrm{~h}$ e pareceu ter finalizado após $24 \mathrm{~h}$ permanecendo apenas algumas gotas de diâmetros menores. Os tratamentos T4 (4\%) e T5 (5\%) apresentaram menor quantidade de bolhas desde o primeiro tempo, e não apresentaram crescimento elevado em comparação com os outros. 
Vê-se que as bolhas dos tratamentos que continham carragena em concentrações crescentes não apresentaram estabilidade, como pode ser observado pelos seus desaparecimentos em todos os tratamentos. Isso se deu, possivelmente, por houver formação de interações complexas entre as proteínas do soro de leite e a carragena que diminuíram a capacidade das proteínas de formarem filmes e a película que envolve e estabiliza as bolhas como indicado por Stone e Nickerson, (2012). Além disso, Zheng, et al., (2018) mostraram que a associação da carragena com proteína produzem géis proteicos mais firmes, por tornar as proteínas do soro de leite mais resistente ao desdobramento, o que pode ser prejudicial ao uso da solução em questão como encapsulante.

A movimentação e modificações observadas nas gotas podem ter ocorrido por três outros motivos complementares que ocorrem simultaneamente nas soluções, o movimento Browniano, a maturação de Ostwald (FRANZOL e REZENDE, 2015) e a coalescência, que são comuns em sistemas termodinamicamente instáveis devido às repulsões eletrostáticas entre os componentes das dispersões (FENNEMA, DAMODARAN e PARK, 2010) e caracterizam-se pelo rompimento do fino filme que recobre gotas próximas forçando a união entre elas e pela dissolução do material de dentro no material de fora fazendo com que a pressão interna aumente e cause o crescimento de algumas partículas em função do desaparecimento de outras (FRANZOL e REZENDE, 2015). Além disso YANG, et. al., 2020 dizem que interfaces fracas e móveis podem ser obtidas na calha de Langmuir o que explica espalhamento do material presente na interface e consequentemente o desaparecimentos das partículas.

As bolhas apresentaram valores máximos em torno de $645,09 \mu \mathrm{m} ; 711,38 \mu \mathrm{m}$; $642,93 \mu \mathrm{m} ; 638,55 \mu \mathrm{m}$; e $232,78 \mu \mathrm{m}$ e mínimos $69,75 \mu \mathrm{m} ; 48,65 \mu \mathrm{m} ; 62,87 \mu \mathrm{m} ; 111,96 \mu \mathrm{m}$;

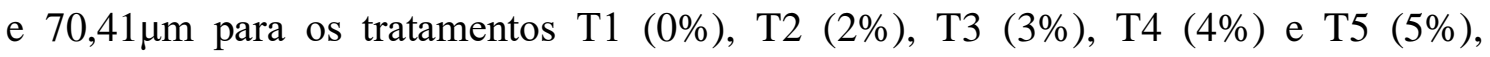
respectivamente. De acordo com YANG, et. al., 2020 as partículas de proteínas do soro de leite isalada podem apresentar valores de escala nanoméricas, porém, eles afirmam que a medida que as proteínas se encontram em sistemas agregados que esses valores podem aumentar como foi observado neste trabalho, onde houve uma solução agregando diversos compostos. Observou-se que os diâmetros variaram em relação ao tempo de captura das imagens com o teor de carragena. No ajuste de curvas por regressão, a equação de Hubbert foi a que apresentou os melhores resultados.

A Tabela 4 mostra as 5 equações obtidas da relação entre o tempo e o teor de carragena na solução encapsulante. As curvas referentes são mostradas na Figura 5. 
Tabela 1 - Equações de Hubbert obtidas, por análise de regressão, relacionando o tempo de captura das imagens, com o diâmetro médio das gotas nos tratamentos

\begin{tabular}{|c|c|c|c|c|}
\hline Tratamento & $\begin{array}{c}\text { Relação } \\
\text { Percentual de } \\
\text { carragena }\end{array}$ & Equação & $\mathrm{R}^{2}$ & \\
\hline $\mathrm{T} 1$ & 0 & $D m=192+\frac{4308 e^{x}}{1+e^{-x}}$ & 0,93 & (8) \\
\hline $\mathrm{T} 2$ & 2 & $D m=\frac{2500 e^{\left(\frac{x-2,3}{0,81}\right)}}{1+e^{-\left(\frac{x-2,3}{1,81}\right)}}$ & 0,98 & (9) \\
\hline $\mathrm{T} 3$ & 3 & $\begin{array}{l}\text { Dm } \\
=-113+\frac{2524 e^{\left(\frac{x-2,8}{1,1}\right)}}{1+e^{-\left(\frac{x-2,8}{1,1}\right)}}\end{array}$ & 0,98 & (10) \\
\hline $\mathrm{T} 4$ & 4 & $D m=101+\frac{2348 e^{\left(\frac{x-2}{0,4}\right)}}{1+e^{-\left(\frac{x-2}{0,4}\right)}}$ & 0,97 & (11) \\
\hline T5 & 5 & $D m=\frac{1068 e^{\left(\frac{x-2,4}{0,95}\right)}}{1+e^{-\left(\frac{x-2,4}{0,95}\right)}}$ & 0,96 & (12) \\
\hline
\end{tabular}

$\mathrm{X}$ : Tempo (h).

Dm: Diâmetro médio

Fonte: própria

Figura 5 - Relação entre o diâmetro e o tempo da captura de microcápsulas de açaí com diferentes relações proteína do leite/carragena

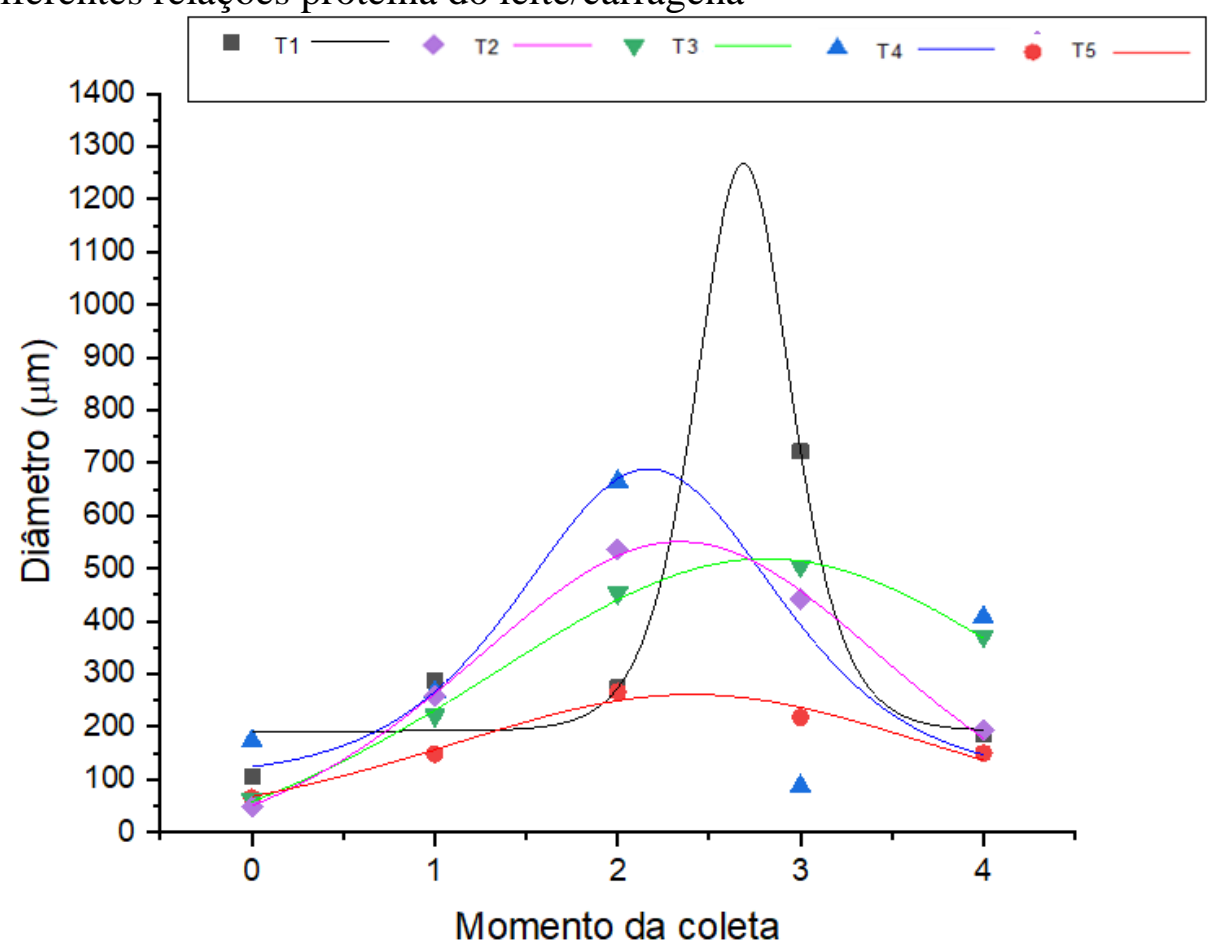

Tempo (h)

Legenda: $\mathrm{T} 1=0 \%$ carragena, $\mathrm{T} 2=1 \%$ de carragena, $\mathrm{T} 3=3 \%$ de carragena, $\mathrm{T} 4=4 \%$ de carragena e $\mathrm{T} 5=5 \%$ de carragena. Fonte: própria 
À medida que o teor de carragena aumentou, houve uma tendência a diminuição no tamanho das gotas, com exceção do tratamento com $4 \%$ de carragena. O tratamento 5\%, apresenta um comportamento mais estável, com diâmetros menores.

Com o passar do tempo, o diâmetro das cápsulas aumentou até atingir um pico e depois começou a diminuir. Embora não tenhamos encontrado na literatura referências para comparar este efeito, ele possivelmente se deu pela incorporação inicial de ar que, ao sair do produto, acabou forçando a união de capsulas que, a posteriori, se separaram novamente, quiçá por ação de forças eletrostáticas. Também se observou que o aumento na quantidade de carragena retardou o tempo do pico e diminuiu o seu valor.

Pelais (2007), observou que o diâmetro médio das gotículas de óleo da polpa de açaí aumentou devido ao alto teor proteico e lipídico. Segundo esta autora o açaí forma uma emulsão estável após o despolpamento com pouca repulsão eletrostática entre gotículas em razão da presença de fosfolipídios e proteínas que são adsorvidos na interface e dão a estabilidade necessária à essa emulsão. Logo a presença de proteína mistura com a polpa de açaí pode ter função encapsulante e não ter função estabilizante e a adição de diferentes teores de carragena não contribui para manter a estabilidade das microcápsulas o que foi verificado por meio das variações observadas nos diâmetros em função dos tempos de captura das imagens. Logo, o tratamento testemunha (que não contém carragena) apresentou-se como o mais favorável para ser aplicado ao encapsulamento da polpa de açaí.

\section{Conclusões}

Diante das verificações observadas neste trabalho, é possível concluir que muitas são as variáveis que precisam ser estudadas previamente quando se tem a intenção de encapsular compostos, principalmente quando envolve materiais de parede com natureza molecular distinta como é o caso das proteínas do soro de leite e da carragena e observouse também que o transcorrer do tempo é um fator limitante entre o preparo das amostras e a hora da secagem, pois favorece que reações indesejáveis aconteçam e alterem a solução estudada. Nesse sentido, as alterações observadas foram principalmente na cor e no tamanho das partículas, pois o teor de sólidos e o $\mathrm{pH}$ não foram afetados com as condições estudadas. Sendo que o teor de sólidos na concentração estudada apresentou um bom indicador para o encapsulamento bem-sucedido, já o pH se mostrou como um ponto crítico desse estudo, pois as proteínas podem reagir de maneira contrária ao que se espera no encapsulamento, quando elas estão distantes do seu ponto isoelétrico. Em relação ao estudo da cor pode-se observar alterações visualmente indesejáveis, principalmente quanto ao escurecimento das amostras. Outra consideração a ser feita 
nesse estudo é que os tamanhos das gostas não apresentaram estabilidade, sendo alterados tanto pelo tempo quanto pela presença da carragena na solução, podendo ser resultado da sua ineficiência para estabilizar as gostas, pelo intervalo muito espaçado de tempo ou mesmo pela concentração usada. Por isso, propõe-se que essas variáveis sejam rearranjadas em novos trabalhos.

\section{Referências}

AOAC - ASSOCIATION OF OFFICIAL ANALYTICAL CHEMISTS. Official methods of Analysis. 20. ed. Gaithersburg: Maryland, 2016.

ARAÚJO, J. M. A. Química de Alimentos: Teoria e prática. $3^{\text {a }}$ ed. Organizado por UFV. Viçosa-MG. 2006.

BARRETT, B. Viral Upper Respiratory Infection. Integrative Medicine: Fourth Edition (Fourth Edition). Elsevier Inc. 2018.

BERTALMÍO, M. Colour representation and colour gamuts. Vision Models for High Dynamic Range and Wide Colour Gamut Imaging, 131-155, 2020.

CARMONA, P. A. O. Secagem por atomização e microencapsulação de óleo de laranja: estudo das propriedades da emulsão e do tipo de material de parede sobre as características do pó, Dissertação de Mestrado apresentada à Faculdade de Engenharia de Alimentos da Universidade Estadual de Campinas para obtenção do Título de Mestre em Engenharia de Alimentos., p. 154. 2011.

CARNEIRO, H. C. F. Microencapsulação de óleo de linhaça por spray drying: influência da utilização de diferentes combinações de materiais de parede. Dissertação de mestrado em engenharia de Alimentos. Faculdade de Engenharia de Alimentos. Campinas: Universidade Estadual de Campinas. 2011.

CHUYEN, H. V., ROACH, P. D., GOLDING, J. B., PARKS, S. E., e NGUYEN, M. H. Encapsulation of carotenoid-rich oil from Gac peel: Optimisation of the encapsulating process using a spray drier and the storage stability of encapsulated powder. Powder Technology, 344, 373-379, 2019.

FAVARO-TRINDADE, C.S.; PINHO, S.C.; ROCHA, G.A. Microencapsulação de ingredientes alimentícios. Brazilian Journal of Food Technology, Campinas, v.11, p.103-112, 2008.

FENNEMA, O. R., DAMODARAN, S. E PARK, K. L. Química de Alimentos de Fennema. $4^{\mathrm{a}}$ ed. Organizado por artmed. Porto Alegre - RS. 2010.

FRANZOL, A; REZENDE, M. C. Estabilidade de emulsões: um estudo de caso envolvendo emulsionantes aniônico, catiônico e não-iônico. Polímeros v.25, São Carlos - SP. 2015.

GHARSALLAOUI, A.; ROUDAUT, G.; CHAMBIN, O.; VOILLEY, A.; SAUREL, R. Applications of secagem por spray in microencapsulation of food ingredients: An overview. Food Research International, v.40, n.9, p.1107-1121, 2007. 
JAFARI, S. M., GHALENOEI, M. G. DEHNAD, D. Influência da secagem por atomização no índice de solubilidade em água, densidade aparente e teor de antocianinas do suco de romã em pó, Dryer Techlogy, v. 311, p. 59-65. 2017.

JAFARI, S. M.; ASSADPOOR, E.; HE, Y.; BHANDARI, B. Encapsulation efficiency of food flavors and oils during spray drying. Drying Technology, v.26, n.7, p.816-835, 2008 .

JAYASUNDERA, M.; ADHIKARI, B.; ALDRED, P.; GHANDI, A. Surface modification of spray dried food and emulsion powders with surface-active proteins: A review. Journal of Food Engineering, v.93, p.266-277, 2009.

KANG, J., THAKALI, K. M., XIE, C., KONDO, M., TONG, Y. OU, B., JENSEN, G., MEDINA, M. B., SCHAUSS, A.G. WU, X. Bioactivities of açaí (Euterpe precatoria Mart.) fruit pulp, superior antioxidant and anti-inflammatory properties to Euterpe oleracea Mart., Food Chemistry, v. 133, n. 3, p. 671-677. 2012.

KULKARNI, V. S., e SHAW, C. Use of Polymers and Thickeners in Semisolid and Liquid Formulations. Essential Chemistry for Formulators of Semisolid and Liquid Dosages, 43-69, 2016.

KYRIAKOUDI, A., e TSIMIDOU, M. Z.. Properties of encapsulated saffron extracts in maltodextrin using the Büchi B-90 nano spray-dryer. Food Chemistry, 266 (April), 458$465,2018$.

LAURENTI, E. e GARCIA, S. Eficiência de materiais encapsulantes naturais e comerciais na liberação controlada de probiótico encapsulado Efficiency of natural and commercial encapsulating materials, Brazilian Journal of Food Technolog J. Food Technol, Campinas, v. 16, n. 2, p. 107-115. 2013.

MCKEEN, L. W. Introduction to the Physical, Mechanical, and Thermal Properties of Plastics and Elastomers. In The Effect of Long Term Thermal Exposure on Plastics and Elastomers (pp. 43-71), 2014.

MUZAFFAR, K., WANI, S. A., DINKARRAO, B. V., KUMAR, P. Determination of production efficiency, color, glass transition, and sticky point temperature of spray- dried pomegranate juice powder, Cogent Food \& Agriculture, v. 15, n. 1, p. 2-7. 2016.

PELAIS, C. A. N., Estudo dos fatores que influenciam na estabilidade da emulsão do açaí. Dissertação de Mestrado apresentada ao Programa de Pós-graduação em Ciência e Tecnologia de Alimentos da Universidade Federal do Pará, para obtenção do grau de Mestre em Ciência e Tecnologia de Alimentos. Belém-PA, 2007.

PORTINHO, J.A; Zimmermann, L. M; Bruck, M. R. Efeitos Benéficos do Açaí. International Journal of Nutrology, v.5, n.1, p. 15-20, jan./abr. 2012.

SANTANA, A. A. et al. CANO-HIGUITA, D. M; OLIVEIRA, R. A; TELIS, V. R. N., Influence of different combinations of wall materials on the microencapsulation of jussara pulp (Euterpe edulis) by spray drying”, Food Chemistry, v.212, p. 1-9. 2016.

SANTOS, F. G. Preparação de micro/nanopartículas de poliuretano Biodegradável carreadoras de óleo de açaí e A - tocoferol. Dissertação para a obtenção do título de mestre em engenharia e tecnologia de materiais. Porto Alegre, 2014. 
SCHRODER, A; BERTON-CARABIN, C; VENEMA; P. CORNACCHIA, L. Interfacial properties of whey protein and whey protein hydrolysates. Food Hydrocolloids v.73 129$140,2017$.

STONE, A. K. E NICKERSON, M. T. Formation and functionality of whey protein isolate e (kappa-, iota-, and lambda-type) carrageenan electrostatic complexes, Food hydrocolloids, n. v. 27(2), p. 271-277. 2012.

TONON, R. V; GROSSO, C.R.F; HUBINGER, M. D. Influence of emulsion composition and inlet air temperature on the microencapsulation of flaxseed oil by spray drying. Faculty of Food Engineering, University of Campinas, P.O. Box 6121, 13083-862, Campinas, SP, Brazil. 2011.

WALSTRA, P. The role of proteins in stabilization of emulsions. In KAUSHIK, V.; ROOS, Y.H.O. Limonene encapsulation in freeze-drying of gum Arabic-sucrose- gelatin systems. Journal of Food Engineering, v.40, p.1381-1391, 2007.

YANG, J., THIELEN, I., BERTON-CARABIN, C. C., VAN DER LINDEN, E., e SAGIS, L. M. C. Nonlinear interfacial rheology and atomic force microscopy of air-water interfaces stabilized by whey protein beads and their constituents. Food Hydrocolloids, 101(May), 105-466, 2020.

ZHENG, H. BEAMER, S.K. MATAK, K. E. JACZYNSKI, J. Effect of $\kappa$-carrageenan on gelation and gel characteristics of Antarctic krill (Euphausia superba) protein isolated with isoelectric solubilization/precipita-tion, Food Chemistry. 2018.

ZÍLIO, S. C. Óptica Moderna, IFSC-USP, p. 300. 2009. 